\title{
Erratum to: Hypersplenism is correlated with increased risk of hepatocellular carcinoma in patients with post-hepatitis cirrhosis
}

\author{
Xing $\mathrm{Lv}^{1} \cdot$ Fan Yang ${ }^{2} \cdot$ Xin Guo ${ }^{1} \cdot$ Tao Yang $^{3} \cdot$ Ti Zhou $^{1} \cdot$ Xiaoping Dong $^{4}$. \\ Yong Long ${ }^{5} \cdot$ Dan Xiao $^{5} \cdot$ Yong Chen ${ }^{1}$
}

Published online: 5 May 2016

(C) International Society of Oncology and BioMarkers (ISOBM) 2016

Erratum to: Tumor Biol.

DOI 10.1007/s13277-015-4764-5

The author missed to include Yong Long as the cocorresponding author for this published online paper.

Yong Long is already included as co-corresponding author as shown below.

The online version of the original article can be found at http://dx.doi.org/ 10.1007/s13277-015-4764-5.

\footnotetext{
Yong Chen

yongchen62@yahoo.com
}

$\triangle$ Yong Long

longyong@fmmu.edu.cn

1 Department of Hepatobiliary Surgery, Xijing Hospital, Fourth Military Medical University, Xi'an, Shaanxi 710032, People's Republic of China

2 Department of C Area of General Surgery, The First Affiliated Hospital of Inner Mongolia Medical College, Inner Mongolia 010000, People's Republic of China

3 Department of General Surgery, Tangdu Hospital, Fourth Military Medical University, Xi'an, Shaanxi 710038, People's Republic of China

4 Department of Cerebral Surgery, Tangdu Hospital, Fourth Military Medical University, Xi'an, Shaanxi 710038, People's Republic of China

5 Department of Epidemiology, Fourth Military Medical University, Xi'an, Shaanxi 710032, People's Republic of China 